ingly admits some of these (page 8): nothing on Tibet, nor on the Theravādin tradition in Sri Lanka or Burma, nor on Cambodia, Vietnam or China, nor on feminism. However, his defence of these shortcomings is weak: namely, that these just reflect the lack of research to date into these areas. In fact there already exists published work on Tibetan perspectives that could have been reprinted, and further work on all of these areas presumably could have been commissioned. Furthermore, as Keown does not specifically acknowledge, the volume is also weak on philosophy. Obviously, there already exists in the West a very large body of rigorous philosophical discussion on the issue of abortion, critically examining the rationality of the moral and non-moral judgments that supposedly justify various stands on the matter. It is regrettable that this volume includes no sustained attempt to engage with Buddhist views on abortion from that disciplinary perspective.

It is also regrettable that a book as expensive as this one should include a number of typographical lapses, the most serious of which is the omission (on pages 119-120) of what I estimate to be a full page of notes to Harrison's essay.

Notwithstanding these limitations, however, this is an interesting and worthwhile book that breaks quite a bit of new ground (particularly on the descriptive side). As such, it represents an initiative in cross-cultural bioethics that very much deserves to be built upon.

ROY W PERRETT

School of History, Philosophy E Politics, Massey University

\section{Alternative Medicine and Ethics}

\author{
Edited by James $M$ Humber and \\ Robert F Almeder, Humana Press, \\ 1998,220 pages, $\$ 44.50 \mathrm{hb}$.
}

Despite the growing popularity of complementary and alternative (CAM) therapies both in the UK and the US, surprisingly little has been written about the ethical dimensions of the holistic CAM relationship. Such literature as there is often transposes the discourse of medical ethics to the CAM relationship mutatis mutandis, overlooking the substantial differences between the nature of the professional relationships. Arguably, the ethical concerns which affect the CAM relationship, which is essentially subjective, holistic and intuitive, are very different from those arising in an orthodox relationship which is, characteristically objective, symptombased and rational. When considering beneficence, for example, "healing" in the CAM sense takes on a much broader definition, referring to improvements which can occur on an emotional, psychological or spiritual level, without the patient necessarily being cured of specific disease symptoms.

Alternative Medicine and Ethics is certainly a useful starting point for debate. This multi-authored text includes thought-provoking chapters on orthodox practitioners as gatekeepers to CAM, insurance coverage for CAM, and ethical and legal dilemmas surrounding prayer as a method of alternative healing for children. Although written from an American perspective, the issues are extremely pertinent in the UK, where a major initiative, established by $\mathrm{HRH}$ The Prince of Wales, is currently looking at the whole area of integration of CAM and orthodox medicine.

Ever since the passing of the Quacks' Charter of 1542, the status of complementary medicine has been the subject of sustained political debate. Indeed, what has linked over 150 diverse therapeutic approaches in the past is their exclusion from what has been taught in orthodox medical schools, and the unwillingness of insurers to pay for them. Even the choice of nomenclature - "complementary" or "alternative" - represents the divide as to whether therapists see themselves as supplementary to orthodox medicine or as a genuine alternative, and it is interesting that this book chooses the latter term, whereas in the UK the preferred term is "complementary", and increasingly, we read of "integrated medicine".

Those alternative practitioners who regard the medical profession's antipathy towards CAM as having more to do with medical territorialism and less to do with the best interests of patients will find no comfort in the book's forthright opening chapter: "Alternative medicine: more hype than hope". In fact, this tirade by Stephen Barrett is almost comical in its one-sidedness. As though side effects and iatrogenic illness did not exist, he writes: "With safe and effective medicines available, treatment with herbal products makes little sense". So much for promoting patient choice!
Weitzman, in his chapter on insurance coverage, by way of contrast, takes as his starting point the much quoted findings from a 1993 survey that nearly one in three of the population in the US used some form or other of CAM therapy, spending $\$ 13.7$ billion out of their own pockets for services not covered by health plans. Patel's chapter, "Understanding the integration of alternative modalities into an emerging healthcare model in the United States", provides a thoughtful analysis of what integration might mean in practice and what might be lost by forcing CAM therapies, which traditionally offer a compassionate, caring and humane approach, into the environs of orthodox medicine. In doing so, he poses critical questions about how the Cartesian/ Newtonian biomedical model can be reconciled with the mind-body philosophies underpinning CAM therapies.

The chapters on health plans as gatekeepers and insurance coverage for alternative medicine may need some translation for a UK readership, but the central issues are the same on both sides of the Atlantic, namely the reluctance to integrate or fund CAM therapies which are not substantiated by scientific research at a time when orthodox medicine is being increasingly driven in an evidence-based direction. Again, although drawing entirely on US case law, Neeley's chapter on "Prayer as a method of alternative healing" raises fundamental issues about parental rights of decision making, and whether it can ever be right to abandon orthodox medicine in favour of CAM approaches for one's children, a question which is yet to reach the British courts.

This is a fascinating book which deserves a wide readership. As well as its obvious interest to complementary and alternative therapists, it raises important general issues of health care ethics and law. It should certainly be read by general practitioner and health authority purchasers who may be interested in purchasing CAM therapies, and will, it is to be hoped, be taken up by the growing number of medical schools offering special study modules in this subject.

\section{JULIE STONE}

Senior Lecturer in Health Care Ethics and Law, University of Greenwich School of Health 